\title{
Comparative study of the effect of an acidic anion on the mild steel corrosion inhibition using Rhus Coriaria plant extract and its quercetin component
}

\author{
K. M. Hijazi ${ }^{1, *}$, A. M. Abdel-Gaber ${ }^{2,3}$, G. O. Younes ${ }^{4}$ and Roland Habchi ${ }^{5}$ \\ ${ }^{I}$ Department of Art and Science, Lebanese American University, \\ P.O. Box 135053 Beirut, Lebanon \\ ${ }^{2}$ Faculty of Science, Department of Chemistry, Beirut Arab University, Debbieh Main Road, \\ P.O.Box 11-5020 Beirut, Lebanon \\ ${ }^{3}$ Faculty of Science, Department of Chemistry, Alexandria University, \\ P.O.Box 426 Alexandria, Egypt \\ ${ }^{4}$ Faculty of Science, Department of Chemistry, Beirut Arab University, Debbieh Main Road \\ P.O.Box 11-5020 Beirut, Lebanon \\ ${ }^{5}$ Department of Science, Lebanese University, Al Fanar Campus \\ Research Platform for Nanosciences and Nanotechologies, Al Fanar, Lebanon
}

*Corresponding author: khadija.safadi@lau.edu.lb

Received 25/06/2018; accepted 12/12/2020

https://doi.org/10.4152/pea.2021390402

\begin{abstract}
The use of plant extracts as corrosion inhibitors has been increasing greatly in recent studies. The inhibitive effect of sumac, Rhus Coriaria (RC), a Lebanese plant, and Quercetin, one of its chemical constituents, on mild steel corrosion, in $0.5 \mathrm{M} \mathrm{HCl}$ and 0.5 $\mathrm{M} \mathrm{H}_{2} \mathrm{SO}_{4}$ solutions, was studied using electrochemical impedance spectroscopy (EIS), potentiodynamic polarization, atomic force spectroscopy (AFM) and Fourier infrared spectroscopy (FTIR) techniques. Potentiodynamic polarization curves indicated that both $\mathrm{RC}$ and its chemical constituent, Quercetin, behave as a mixed type inhibitor in both acidic media. The dissolution process of RC and Quercetin occured under activation control, as showed by EIS measurements, and the corrosion inhibition is the result of the inhibitor adsorption onto the metal surface. Inhibition by RC extract was found to be greater in $0.5 \mathrm{M} \mathrm{HCl}$ than in $0.5 \mathrm{M} \mathrm{H}_{2} \mathrm{SO}_{4}$ solutions; $\mathrm{RC}$ extract also proved to be a better inhibitor than its chemical constituent, Quercetin, in both acids. Thermodynamic parameters indicate that the inhibition process on the steel surface was due to spontaneous physical adsorption of RC and Quercetin onto it. The adsorption model was found to obey thermodynamic-kinetic model and Flory-Huggins model. Surface analysis by AFM spectroscopy investigated the formation of the adsorbed protective film onto the mild steel surface.
\end{abstract}

Keywords: corrosion, mild steel, electrochemical, leaf extract, Quercetin, AFM. 


\section{Introduction}

Combating metal corrosion in acidic media is a long-standing effort of scientists and engineers. Due to the corrosive effect of these acids and to the huge economic loss that is suffered by the concerned industries resulting from rapid corrosion of metallic parts, many chemical compounds have been used to reduce and control this process. Suitable inorganic and organic inhibitors have shown good anticorrosive activity [1, 2]. Many of these compounds have proved to be highly efficient in corrosion inhibition, but their use is still limited, due to their toxicity and ecological risks [3]. Because of this, attention has been drawn towards the use of natural products as corrosion inhibitors, due to their biodegradability and low cost [4]. This advantage gives them the opportunity to replace the expensive and toxic chemical inhibitors. The corrosion inhibition abilities of different plant extracts differ from one type to another, depending on the used part of the plant and of its location [5]. Some plant extracts have been studied as effective steel corrosion inhibitors in $\mathrm{HCl}$ and $\mathrm{H}_{2} \mathrm{SO}_{4}$ solutions, as reported in [6-11]. The present work reports the inhibition effect of Sumac leaf extract, Rhus Coriaria (RC), and its chemical constituent, Quercetin, on mild steel corrosion, in $0.5 \mathrm{M} \mathrm{HCl}$ and $0.5 \mathrm{M} \mathrm{H}_{2} \mathrm{SO}_{4}$ solutions. The difference in the inhibition effect of $\mathrm{RC}$ plant extract with Quercetin is herein discussed. It is expected to provide a link between the RC inhibition effect and that of its chemical constituent, Quercetin, on mild steel corrosion in acidic solutions. The novelty of this study is that it sheds some light on the effect and interaction of the acidic anion with the plant extract (RC) and Quercetin, and on its contribution to mild steel corrosion inhibition. Thermodynamic studies provide a great link on the effect of the acidic anion and its correlation with mild steel corrosion retarding.

\section{Experimental}

\section{Solution preparation}

The tested solutions were prepared using distilled water and analytical grade reagents, $\mathrm{HCl}$ and $\mathrm{H}_{2} \mathrm{SO}_{4}$, obtained from $\mathrm{BDH}$ chemical company. Quercetin with $\geq 95 \%$ purity was obtained from Sigma Aldrich. The plant leaf was dried for $2 \mathrm{~h}$ in an oven at $80{ }^{\circ} \mathrm{C}$, after which it was grinded into powdery form, from which stock solutions of plant extracts were prepared. A mass of $10 \mathrm{~g}$ of the grinded powder plant leaf was refluxed in $100 \mathrm{~mL}$ of distilled water for $2 \mathrm{~h}$, and then filtered to remove any contamination. From the filtrate, a volume of $10 \mathrm{~mL}$ was evaporated, and the obtained residue was weighed and further used in the preparation of the stock solution concentration. Different concentrations of the extract, in $0.5 \mathrm{M} \mathrm{HCl}$ or $0.5 \mathrm{M} \mathrm{H}_{2} \mathrm{SO}_{4}$, were prepared by adding $4 \mathrm{M} \mathrm{HCl}$ or $4 \mathrm{M} \mathrm{H}_{2} \mathrm{SO}_{4}$ to the required volume of the stock solution of the plant leaf extract, and mixed with double distilled water.

\section{Electrochemical studies}

A frequency response analyzer (FRA)/potentiostat supplied from ACM instruments (UK) was used to determine the polarization and electrochemical 
impedance measurements. The detailed electrochemical techniques were reported in a previous publication [12].

\section{FTIR analysis}

The FTIR spectra of RC leaf extract were analyzed at Faculty of Engineering and Physical Sciences, University of Surrey (UK), using a solid FTIR sample holder. The infrared spectra of the solid sample were recorded using a Perkin-Elmer (2000 FTIR) spectrometer, by averaging 32 scans at a resolution of $4 \mathrm{~cm}^{-1}$ in the spectral region between 4000 and $500 \mathrm{~cm}^{-1}$.

\section{AFM surface morphology}

Atomic force microscopy (AFM), operated in the contact mode, under ambient conditions, with an Agilent 5420 Atomic Force Microscope, was used to determine the morphology of mild steel surface. Solutions of $0.5 \mathrm{M} \mathrm{HCl}$ and $0.5 \mathrm{M}$ $\mathrm{H}_{2} \mathrm{SO}_{4}$, with and without different concentrations of both $\mathrm{RC}$ leaf extract and Quercetin, were immersed for $2 \mathrm{~h}$, with specimens of mild steel, at $25^{\circ} \mathrm{C}$. After that, exposure images of the specimens were recorded using a probe with a maximum measuring area of $100 \times 100$ micrometer. AFM analysis was done at Lebanese University-Fanar Campus, Platform for Research in Nanoscience and Nanotechnologies.

\section{Results and discussion}

\section{Spectrophotometric analysis}

The Lebanese sumac called Rhus Coriaria (RC) contains different chemical compounds. It has a broad range of nutritionally and medicinally significant photochemical components, such as tannins, flavonoids, anthocyanins, organic acids, flavones (such as Myricetin, Quercetin and Kaempferol), proteins, fiber, volatile oils, nitrates and nitrites [13].

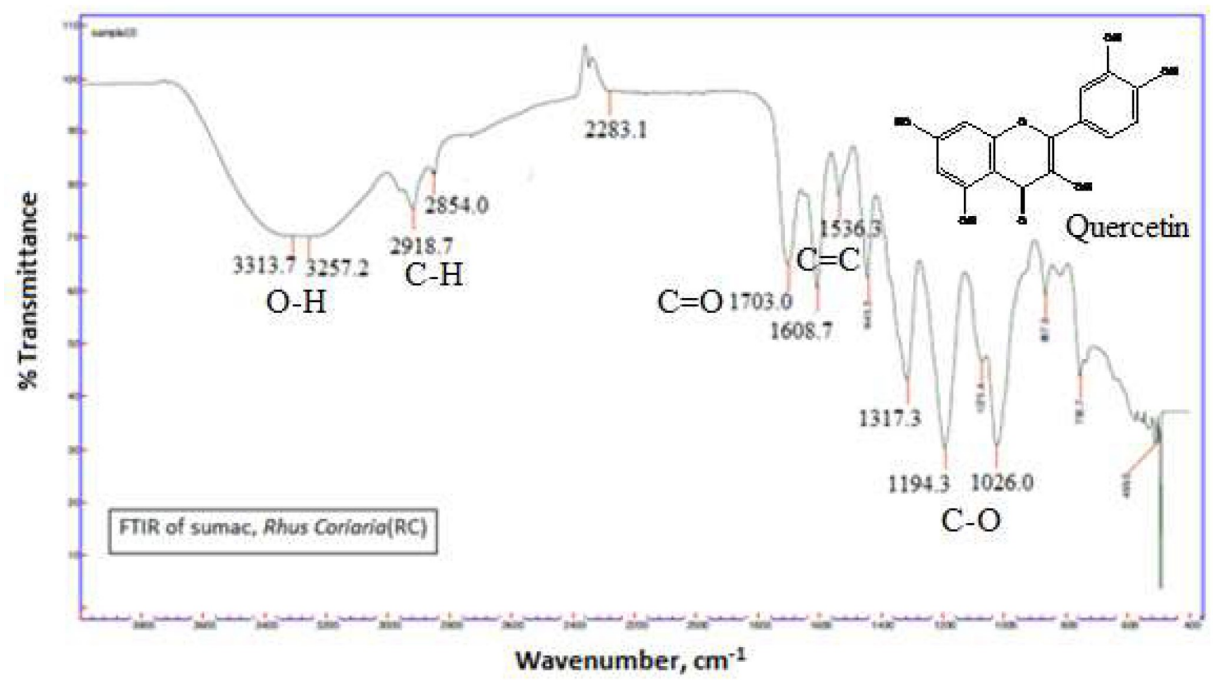

Figure 1. IR spectrum for Rhus Coriaria leaf extract.

Fig. 1 shows the FTIR spectrum of RC leaf extracts. The absorption bands exhibit $\mathrm{C}-\mathrm{H}\left(2918.7 \mathrm{~cm}^{-1}\right), \mathrm{O}-\mathrm{H}\left(3313.7-3257.2 \mathrm{~cm}^{-1}\right), \mathrm{C}=\mathrm{C}\left(1608.7-15363 \mathrm{~cm}^{-1}\right)$ and $\mathrm{C}$ 
$=\mathrm{O}\left(1703 \mathrm{~cm}^{-1}\right)$ stretching vibrations. The strong band around $1194.3-1026.0 \mathrm{~cm}^{-1}$ is assigned to $\mathrm{C}-\mathrm{O}$ single bond. The obtained IR spectrum of $\mathrm{RC}$ leaf extract is in a good agreement with that of the suggested spectrum band of the hydrolyzed form of Quercetin.

\section{Potentiodynamic polarization curves}

The potentiodynamic polarization curves of steel in a $0.5 \mathrm{M} \mathrm{HCl}$ solution, in the absence and presence of 0.75 g. $\mathrm{L}^{-1}$ of $\mathrm{RC}$ and Quercetin, are shown in Fig. 2. A clear shift in both anodic and cathodic parts of the metal dissolution, towards lower values of corrosion current densities, indicates that both RC and Quercetin delay mild steel corrosion. Similar observations were reported for steel in $0.5 \mathrm{M}$ $\mathrm{H}_{2} \mathrm{SO}_{4}$, but still with greater inhibition efficiency for the plant extract, up to $84 \%$ in $\mathrm{HCl}$ media, rather than in sulfuric acid, as reported in Table 1.

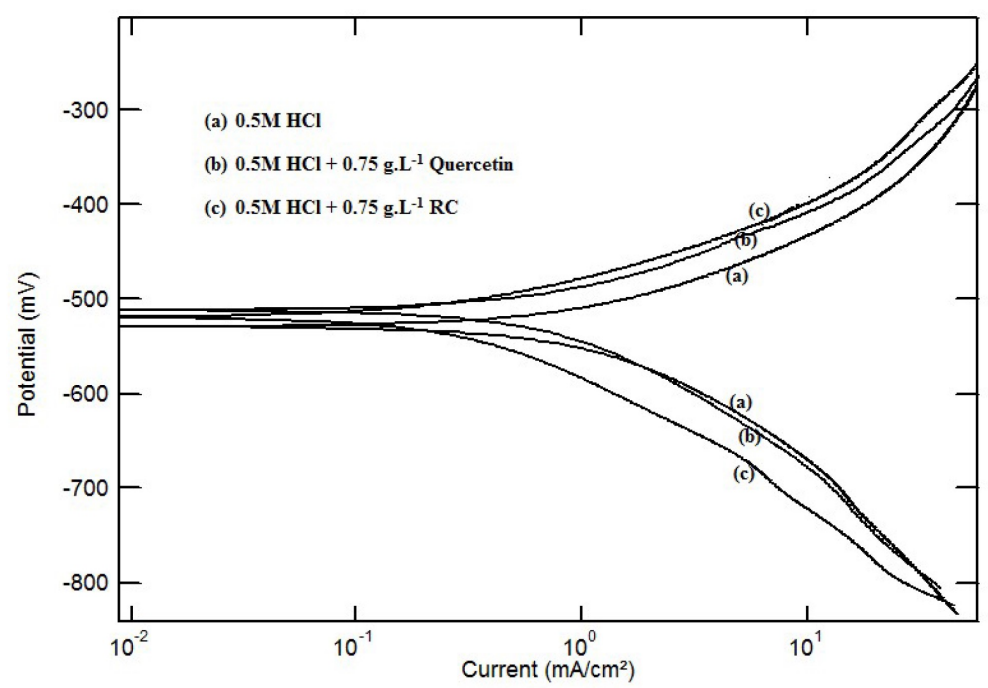

Figure 2. Potentiodynamic polarization curves of steel in $0.5 \mathrm{M} \mathrm{HCl}$, in the absence and presence of 0.75 g. $\mathrm{L}^{-1}$ of Quercetin and RC leaf extract, at $30{ }^{\circ} \mathrm{C}$.

The electrochemical corrosion parameters shown in Table 1 were calculated from polarization measurements, along with the percentage of inhibition efficiency, $\eta$, where $\eta=\left[\left(i_{0}-i\right) / i_{0}\right] \times 100$, and $i_{o}$ and $i$ are the corrosion current densities in the absence and presence of plant leaf extracts, respectively.

$[10,14]$ show clearly that corrosion current density ( $\left.i_{\text {corr }}\right)$ decreases considerably with the addition of the plant extract and of Quercetin.

The inhibition efficiency, $\eta$, increases as the plant extract concentration increases and reaches a maximum efficiency of $84 \%$ at $80 \mathrm{ppm}(0.8 \mathrm{~g} / \mathrm{L})$, being assisted by physical adsorption mechanism onto the metal surface. Further increase in the RC concentration showed no more changes in percentage inhibition, indicating that optimum concentration has been reached. Plant extract concentration greater than $0.8 \mathrm{~g} / \mathrm{L}$ gave a constant inhibition efficiency or a small decrease in it.

The appearance of critical concentration, after which the extract inhibitive effect decreased, was also observed in other study [15]. 
Table 1. Electrochemical polarization parameters for mild steel corrosion in $0.5 \mathrm{M} \mathrm{HCl}$ and $0.5 \mathrm{M} \mathrm{H}_{2} \mathrm{SO}_{4}$, in the absence and presence of different concentrations of $\mathrm{RC}$ leaf extract and Quercetin, at $30{ }^{\circ} \mathrm{C}$.

\begin{tabular}{|c|c|c|c|c|c|c|c|}
\hline \multirow{2}{*}{ Acid } & \multirow{2}{*}{$\begin{array}{c}\text { Plant } \\
\text { leaf } \\
\text { extract }\end{array}$} & \multirow{2}{*}{$\begin{array}{l}\text { Conc. } \\
\left(\text { g.. }{ }^{-1}\right)\end{array}$} & \multirow{2}{*}{$\begin{array}{c}-\mathrm{E}_{\mathrm{corr}} \\
(\mathrm{mVvs.SCE})\end{array}$} & $\boldsymbol{\beta}_{\mathbf{a}}$ & $\boldsymbol{\beta}_{\mathbf{c}}$ & \multirow{2}{*}{$\begin{array}{c}\mathbf{i}_{\text {corr }} \\
\left(\mathrm{mA} \mathrm{cm}^{-2}\right)\end{array}$} & \multirow[t]{2}{*}{$\eta$} \\
\hline & & & & \multicolumn{2}{|c|}{ mV/decade } & & \\
\hline \multirow{16}{*}{$0.5 \mathrm{M} \mathrm{HCl}$} & Blank & 0.00 & 520 & 106 & 131 & 1.519 & - \\
\hline & \multirow{8}{*}{$R C$} & 0.10 & 506 & 72 & 100 & 0.662 & 56.0 \\
\hline & & 0.20 & 500 & 77 & 120 & 0.601 & 61.0 \\
\hline & & 0.40 & 508 & 70 & 114 & 0.422 & 72.0 \\
\hline & & 0.50 & 509 & 76 & 107 & 0.313 & 79.0 \\
\hline & & 0.75 & 521 & 72 & 123 & 0.306 & 80.0 \\
\hline & & 0.80 & 519 & 72 & 113 & 0.247 & 84.0 \\
\hline & & 0.85 & 514 & 77 & 110 & 0.264 & 82.0 \\
\hline & & 0.90 & 508 & 76 & 114 & 0.286 & 81.0 \\
\hline & \multirow{7}{*}{ Quercetin } & 0.30 & 503 & 74 & 134 & 1.05 & 31.0 \\
\hline & & 0.75 & 495 & 65 & 133 & 0.88 & 42.0 \\
\hline & & 1.20 & 487 & 67 & 135 & 0.73 & 52.0 \\
\hline & & 1.52 & 492 & 60 & 133 & 0.65 & 57.0 \\
\hline & & 1.81 & 457 & 53 & 138 & 0.54 & 65.0 \\
\hline & & 2.00 & 465 & 66 & 135 & 0.56 & 63.0 \\
\hline & & 2.30 & 455 & 67 & 133 & 0.57 & 62.0 \\
\hline \multirow{18}{*}{$0.5 \mathrm{M} \mathrm{H}_{2} \mathrm{SO}_{4}$} & Blank & 0 & 509 & 82 & 154 & 1.55 & - \\
\hline & \multirow{10}{*}{$\mathrm{RC}$} & 0.20 & 501 & 74 & 140 & 1.15 & 26.0 \\
\hline & & 0.30 & 504 & 75 & 127 & 1.01 & 35.0 \\
\hline & & 0.40 & 495 & 65 & 136 & 0.98 & 37.0 \\
\hline & & 0.60 & 486 & 61 & 132 & 0.85 & 45.0 \\
\hline & & 0.75 & 496 & 62 & 141 & 0.70 & 55.0 \\
\hline & & 1.00 & 491 & 60 & 142 & 0.55 & 65.0 \\
\hline & & 1.20 & 486 & 57 & 136 & 0.43 & 72.0 \\
\hline & & 1.40 & 491 & 62 & 134 & 0.40 & 74.0 \\
\hline & & 1.50 & 496 & 60 & 132 & 0.40 & 74.0 \\
\hline & & 1.55 & 485 & 65 & 134 & 0.41 & 74.0 \\
\hline & \multirow{7}{*}{ Quercetin } & 0.30 & 511 & 85 & 130 & 1.22 & 22.0 \\
\hline & & 0.75 & 498 & 78 & 126 & 1.07 & 30.0 \\
\hline & & 1.20 & 523 & 75 & 121 & 0.86 & 46.0 \\
\hline & & 1.52 & 517 & 69 & 116 & 0.71 & 54.0 \\
\hline & & 1.81 & 496 & 73 & 120 & 0.61 & 61.0 \\
\hline & & 2.00 & 498 & 73 & 124 & 0.62 & 60.0 \\
\hline & & 2.50 & 515 & 75 & 121 & 0.63 & 59.0 \\
\hline
\end{tabular}

The Tafel slopes, $\beta \mathrm{a}$ and $\beta_{\mathrm{c}}$, did not change significantly with the inhibitor addition, which indicates that it does not alter the mechanism of hydrogen evolution and metal dissolution process; inhibition action takes place through a similar mechanism [16]. The addition of RC leaf extract retards mild steel corrosion much more than Quercetin in both acidic media.

The curves obtained from the plot of degree of surface coverage $(\theta=\eta / 100)$ with the RC leaf extract concentration and Quercetin in $0.5 \mathrm{M} \mathrm{HCl}$, shown in Fig. 3, indicate that the inhibition process took place through adsorption. The increase in inhibition, with the inhibitor concentration initial rising part of the curve, reveals an increase in the active extract component adsorbed onto the metal surface. This increased inhibitor adsorption leads to the formation of a protective layer that blocks the active sites on the metal surface and shields it from corrosion. At high 
concentrations, a saturated constant part of the curve is observed, which illustrates the formation of mono-layer films on the metal surface [17]. The curve also shows that RC inhibits the corrosion process more effectively than Quercetin in both acidic solutions.

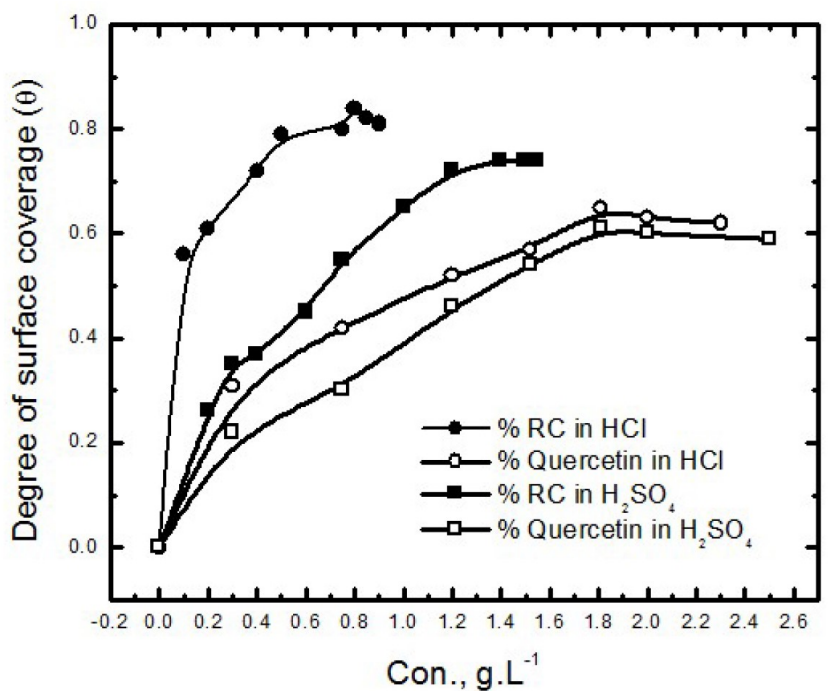

Figure 3. Variations of degree of surface coverage, obtained from polarization measurements, with the RC leaf extract and Quercetin concentrations, in $0.5 \mathrm{M}$ of $\mathrm{HCl}$ and $0.5 \mathrm{M}_{\text {of }} \mathrm{H}_{2} \mathrm{SO}_{4}$.

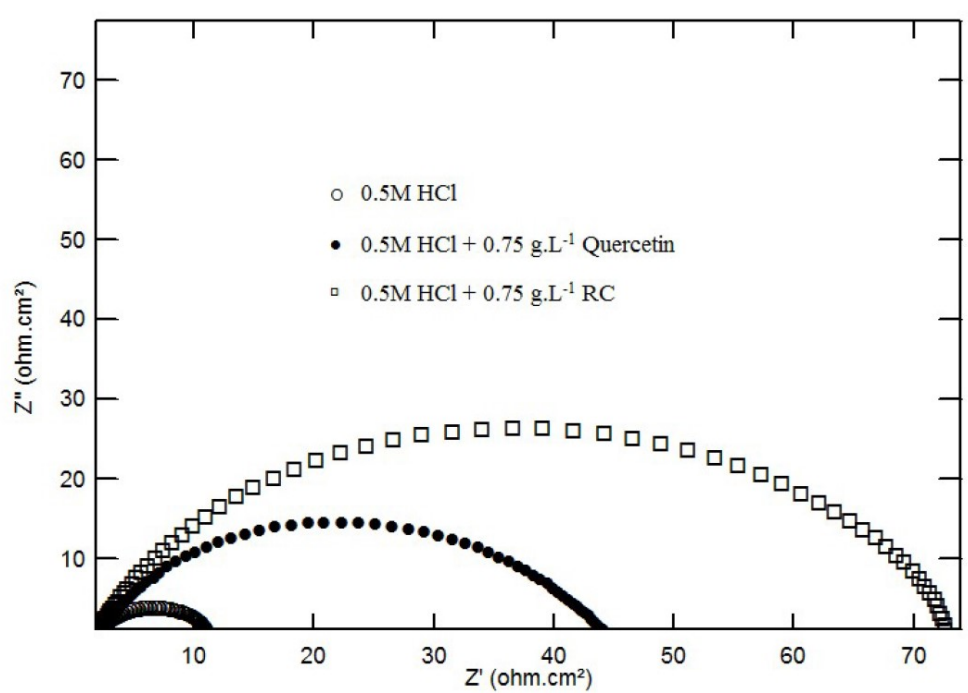

Figure 4. Nyquist plots for mild steel in $0.5 \mathrm{M} \mathrm{HCl}$, in the absence and presence of $0.75 \mathrm{~g} . \mathrm{L}^{-1}$ of RC and of Quercetin, at $30^{\circ} \mathrm{C}$.

\section{Electrochemical impedance spectroscopy measurements}

Steel Nyquist diagram in $0.5 \mathrm{M}$ of $\mathrm{HCl}$ and $\mathrm{H}_{2} \mathrm{SO}_{4}$ solutions containing $0.75 \mathrm{~g}$. $\mathrm{L}^{-1}$ of RC and Quercetin are shown in Fig. 4. The figure exhibits one single depressed semicircle, showing that mild steel corrosion is controlled by charge transfer [16, 17]. The similarities between the observed semicircles for both inhibitors, in the presence of acid alone, and of RC or of its chemical constituent, strongly suggest that the mechanism of metal dissolution is not changed by the inhibitor [6]. 
Similar results were obtained for steel Nyquist impedance plot of in $0.5 \mathrm{M} \mathrm{H}_{2} \mathrm{SO}_{4}$, in the absence and presence of RC leaf extract and Quercetin.

The experimental data obtained from impedance spectra for different Nyquist plots were analyzed by fitting them to a simple equivalent circuit model (Fig. 5), which includes the solution resistance, $R_{s}$, and the constant phase elements (CPE), in parallel to the charge transfer resistance element, $\mathrm{R}_{\mathrm{ct}}$. [18].

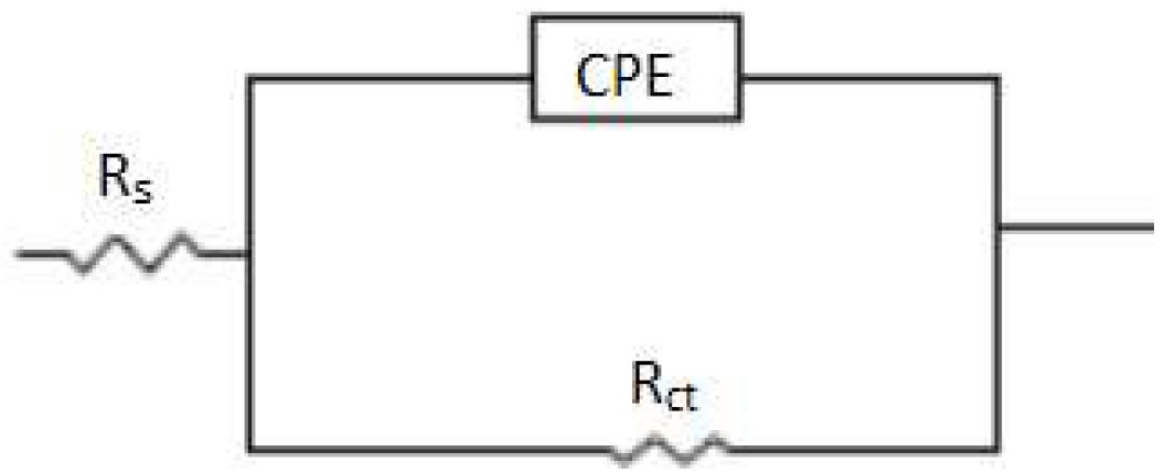

Figure 5. Scheme for the equivalent circuit model.

To compensate for non-homogeneity in the system, the capacitances were implemented as a constant phase element (CPE) that is defined by two values, $Q$ and $n$, which are used to quantify several physical phenomena. The impedance, $Z$, of CPE is presented by:

$$
\mathrm{Z}_{\mathrm{CPE}}=\mathrm{Q}^{-1}(\mathrm{i} \omega)^{-} \mathrm{n}
$$

where $\mathrm{i}=(-1)^{1 / 2}, \omega$ is the frequency in $\operatorname{rad~s}^{-1}, \omega=2 \pi \mathrm{f}$ and $\mathrm{f}$ is the frequency in $\mathrm{Hz}$. If $n$ equals 1 , then, $Z_{\mathrm{CPE}}$ is identical to that of a capacitor, $Z_{C}=(i \omega C)^{-1}$, where $C$ is the ideal double layer capacitance. In fact, a capacitor is actually a constant phase element with a constant phase angle of 90 . For a non-homogeneous system, $n$ values ranges from 0.9 to 1 , and $\mathrm{Q}$ represents the non-ideal double layer capacitance.

From impedance measurements, the percentage inhibition efficiency $(\eta)$ was calculated according to the equation [21]:

$$
\eta=\frac{\text { Rct }- \text { Rct } 0}{\text { Rct }} \times 100
$$

where $R_{c t 0}$ and $R_{c t}$ are the values of the charge transfer resistance $\left(\Omega \mathrm{cm}^{2}\right)$, in the leaf extract absence and presence, respectively.

As it is seen in Table 2, charge transfer resistance $\left(R_{c t}\right)$ values increase with an increasing concentration of RC extract and of Quercetin, while $Q_{\mathrm{dl}}$ decreases with an increasing concentration, suggesting that the inhibitor functions by adsorption onto the steel surface. RC and Quercetin molecules gradually replace water molecules, which leads to the formation of a protective film onto the metal surface, and thus decrease the extent of the metal dissolution [20]. The corrosion inhibition efficiency reached $84 \%$, with 0.75 g. $\mathrm{L}^{-1}$ of $\mathrm{RC}$ concentration. The trend in the increase of $\eta$ is related to the degree of surface coverage of the inhibitor molecule at the steel surface. The high corrosion inhibition efficiency obtained at 
optimum concentration, and which decreases with further increase in concentration, indicates the saturation of the mono adsorbed layer at this concentration. This suggests that mild steel corrosion inhibition in a hydrochloric acid solution took place by an adsorption/desorption mechanism. The concentration of both inhibitors, RC and Quercetin, is high enough to support the adsorbed layer formed at the metal surface and to sustain the process of adsorption/desorption almost at equilibrium, but more shifted towards desorption.

Table 2. Impedance parameters for mild steel in $0.5 \mathrm{M} \mathrm{HCl}$ and $0.5 \mathrm{M} \mathrm{H}_{2} \mathrm{SO}_{4}$ containing different concentrations of RC leaf extract and of Quercetin, respectively, at $30^{\circ} \mathrm{C}$.

\begin{tabular}{|c|c|c|c|c|c|c|}
\hline Acidic solution & $\begin{array}{c}\text { Plant leaf } \\
\text { extract }\end{array}$ & $\begin{array}{l}\text { Conc. } \\
\text { (g. } \text { L }^{1} \text { ) }\end{array}$ & $\begin{array}{c}R_{\mathrm{ct}} \\
\left(\Omega \mathrm{cm}^{2}\right)\end{array}$ & $\begin{array}{c}\mathbf{Q}_{\mathrm{dl}} \\
(\mu \mathrm{F})\end{array}$ & $\mathbf{n}$ & $\eta$ \\
\hline \multirow{20}{*}{$0.5 \mathrm{M} \mathrm{HCl}$} & Blank & 0 & 10.67 & 212 & 0.75 & - \\
\hline & \multirow{12}{*}{$\mathrm{RC}$} & 0.10 & 24.39 & 961 & 0.81 & 56.0 \\
\hline & & 0.20 & 27.27 & 951 & 0.78 & 61.0 \\
\hline & & 0.30 & 32.50 & 914 & 0.75 & 67.0 \\
\hline & & 0.35 & 34.05 & 901 & 0.74 & 69.0 \\
\hline & & 0.40 & 36.20 & 893 & 0.76 & 71.0 \\
\hline & & 0.45 & 41.34 & 782 & 0.71 & 74.0 \\
\hline & & 0.50 & 44.80 & 763 & 0.78 & 76.0 \\
\hline & & 0.65 & 47.65 & 756 & 0.78 & 78.0 \\
\hline & & 0.75 & 51.24 & 882 & 0.78 & 79.0 \\
\hline & & 0.80 & 58.41 & 976 & 0.81 & 82.0 \\
\hline & & 0.85 & 56.32 & 895 & 0.78 & 81.0 \\
\hline & & 0.90 & 56.01 & 888 & 0.76 & 81.0 \\
\hline & \multirow{7}{*}{ Quercetin } & 0.30 & 15.39 & 141 & 0.71 & 31.0 \\
\hline & & 0.75 & 18.60 & 159 & 0.81 & 43.0 \\
\hline & & 1.20 & 22.33 & 158 & 0.79 & 52.0 \\
\hline & & 1.52 & 24.87 & 131 & 0.76 & 57.0 \\
\hline & & 1.81 & 30.12 & 134 & 0.77 & 65.0 \\
\hline & & 2.00 & 30.05 & 142 & 0.76 & 64.0 \\
\hline & & 2.30 & 30.10 & 137 & 0.77 & 64.0 \\
\hline \multirow{19}{*}{$0.5 \mathrm{M} \mathrm{H}_{2} \mathrm{SO}_{4}$} & Blank & 0 & 11.52 & 142 & 0.77 & - \\
\hline & \multirow{11}{*}{$\mathrm{RC}$} & 0.20 & 15.20 & 225 & 0.65 & 24.0 \\
\hline & & 0.30 & 16.97 & 191 & 0.69 & 32.0 \\
\hline & & 0.40 & 18.52 & 103 & 0.75 & 38.0 \\
\hline & & 0.60 & 22.55 & 132 & 0.74 & 49.0 \\
\hline & & 0.75 & 28.19 & 115 & 0.72 & 59.0 \\
\hline & & 1.00 & 34.28 & 154 & 0.69 & 66.0 \\
\hline & & 1.20 & 38.55 & 149 & 0.72 & 70.0 \\
\hline & & 1.40 & 44.50 & 143 & 0.68 & 74.0 \\
\hline & & 1.50 & 33.03 & 109 & 0.75 & 65.0 \\
\hline & & 1.60 & 33.05 & 142 & 0.75 & 65.0 \\
\hline & & 1.80 & 31.97 & 153 & 0.74 & 64.0 \\
\hline & \multirow{7}{*}{ Quercetin } & 0.30 & 14.56 & 186 & 0.77 & 21.0 \\
\hline & & 0.75 & 16.58 & 152 & 0.80 & 30.0 \\
\hline & & 1.20 & 20.13 & 109 & 0.76 & 43.0 \\
\hline & & 1.52 & 24.78 & 166 & 0.74 & 54.0 \\
\hline & & 1.81 & 28.76 & 112 & 0.78 & 60.0 \\
\hline & & 2.00 & 27.80 & 108 & 0.76 & 59.0 \\
\hline & & 2.27 & 28.14 & 109 & 0.74 & 59.0 \\
\hline
\end{tabular}


It is supposed that the thickness of the surface film of adsorbed particles within outer Helmholtz layer (OHL) would shrink, while the disperse part of the double electrical layer would expand [21]. The inhibition efficiencies obtained from both EIS measurements and potentiodynamic polarization curves are very close, which indicates the validity of the results from both techniques. In addition to this, RC leaf extract is a better corrosion inhibitor in $0.5 \mathrm{M} \mathrm{HCl}$ than Quercetin, and, still, $\mathrm{HCl}$ is suppressing $\mathrm{H}_{2} \mathrm{SO}_{4}$ media, as shown in Fig. 4.

\section{AFM surface morphology}

Samples of mild steel immersed in $0.5 \mathrm{M} \mathrm{HCl}$, with and without inhibitor, were studied using atomic force microscope (AFM) to examine their surface morphologies. AFM is best used to identify the surface roughness of the metal samples on a micro scale and to produce $3 \mathrm{D}$ images of the surface $[22,23]$.
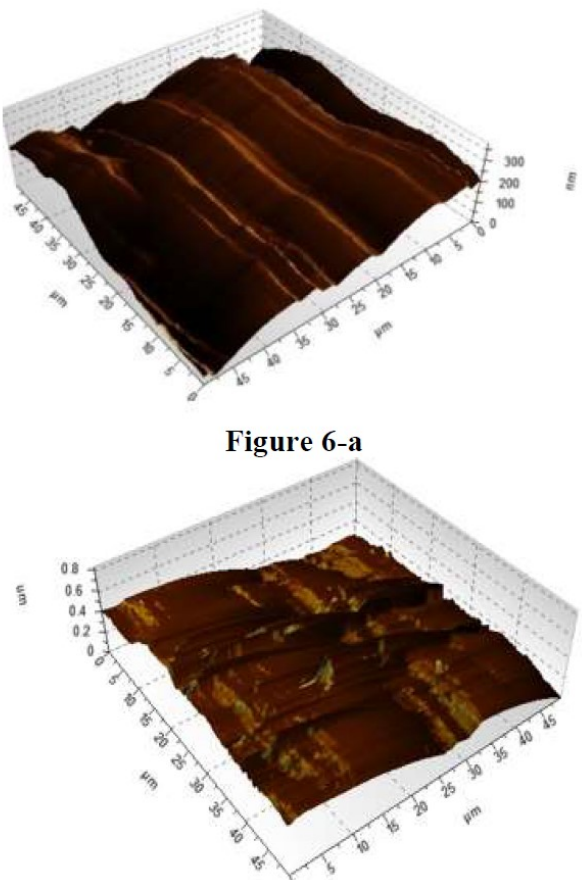

Figure 6-c

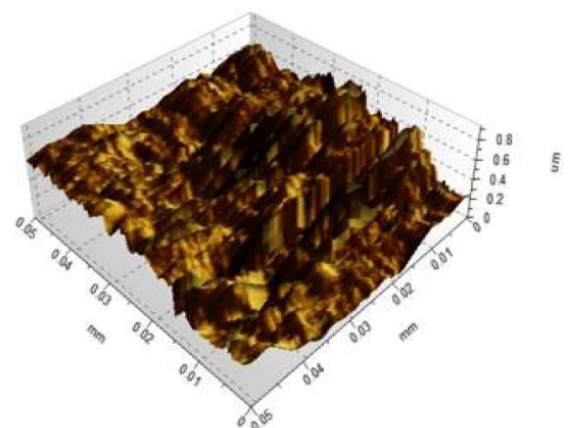

Figure 6-b

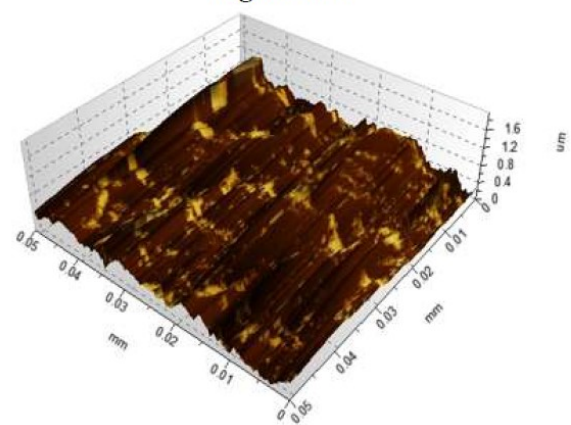

Figure 6-d

Figure 6. Three-dimensional AFM images for steel. Before immersion: (a) bare metal. And after immersion in: (b) $0.5 \mathrm{M} \mathrm{HCl}$; (c) $0.5 \mathrm{M} \mathrm{HCl}+0.75$ g.L $\mathrm{L}^{-1} \mathrm{RC}$; and (d) $0.5 \mathrm{M}$ $\mathrm{HCl}+0.75$ g.L. $\mathrm{L}^{-1}$ of Quercetin, respectively, at $25^{\circ} \mathrm{C}$, for $2 \mathrm{~h}$.

Fig. 6 shows the 3D images obtained before and after $2 \mathrm{~h}$ of metal immersion in a solution with acid alone and with the inhibitor. When mild steel was exposed to a blank $\mathrm{HCl}$ solution, metal dissolution rate was observed to be high (6-b), with a surface full of corrosion products, pits and cavities, in comparison to the surface of pure mild steel (Fig. 6-a). However, in the presence of RC leaf extracts and of Quercetin, the surface roughness of the mild steel was seriously reduced, due to the formation of a protective layer which lowered the corrosion rate, indicating the inhibiting effect of both additives. 
Precise observation showed a smoother mild steel surface, in the presence of RC leaf extract (6-c), in comparison with Quercetin (6-d), indicating that the plant extract still serves as a better and more efficient retarder than chemical compounds, even if Quercetin is one of its chemical constituents. In addition to that, the surface roughness is much more reduced in $\mathrm{HCl}$ than in $\mathrm{H}_{2} \mathrm{SO}_{4}$, even though both acids were equal in concentration, which was $0.5 \mathrm{M}$. This indicates better inhibition efficiency for the plant leaf extract and Quercetin in $\mathrm{HCl}$ media, than of that in $\mathrm{H}_{2} \mathrm{SO}_{4}$, suggesting the greater role that the acidic anion is playing. The surface morphology results obtained on the addition of RC leaf extract and of Quercetin show that a film of adsorbed layer is responsible for corrosion inhibition, confirming results obtained from electrochemical impedance spectroscopy and potentiodynamic polarization measurements, and display a better inhibiting action of RC leaf extract.

\section{Adsorption considerations}

Surface coverage characteristics and the type of adsorption isotherm can play a main role in determining the inhibitor properties. Fitting experimental data into different adsorption isotherms can also provide important information about the inhibition mechanism. Adsorption isotherms can successfully describe the interaction taking place at the surface between the adsorbed inhibitor and the metal [24].

All the obtained values of the surface coverage $(\theta=\eta / 100)$ were fitted to different adsorption isotherms. According to the obtained correlation coefficients, both RC and Quercetin fitted well thermodynamic-kinetic and Flory- Huggins models. The equations describing Flory-Huggins isotherm and kinetic thermodynamic model with their parameters are mentioned in detail in our previous work [12]. The parameters obtained from linear fitting of the mentioned models for RC leaf extract and Quercetin, in $0.5 \mathrm{M} \mathrm{HCl}$ and $0.5 \mathrm{M} \mathrm{H}_{2} \mathrm{SO}_{4}$, at 30 ${ }^{\circ} \mathrm{C}$, are shown in Table 3 .

Table 3. Linear fitting parameters of RC leaf extract and of Quercetin, according to the mentioned models, in $0.5 \mathrm{M} \mathrm{HCl}$, at $30^{\circ} \mathrm{C}$.

\begin{tabular}{|c|c|c|c|c|c|c|c|}
\hline \multirow{2}{*}{ Acid } & \multirow{3}{*}{ Inhibitor } & \multicolumn{3}{|c|}{ Kinetic model } & \multicolumn{3}{c|}{ Flory-Huggins } \\
\cline { 3 - 8 } & & $\mathbf{K}$ & $\mathbf{1 / y}$ & $\mathbf{R}^{\mathbf{2}}$ & $\mathbf{K}$ & $\mathbf{X}$ & $\mathbf{R}^{\mathbf{2}}$ \\
\hline $0.5 \mathrm{M} \mathrm{HCl}$ & $\mathrm{RC}$ & 12.44 & 1.69 & 0.97 & 10.55 & 1.84 & 0.96 \\
\hline $0.5 \mathrm{M} \mathrm{H}_{2} \mathrm{SO}_{4}$ & RC & 1.73 & 0.86 & 0.99 & 1.94 & 0.72 & 0.99 \\
\hline $0.5 \mathrm{M} \mathrm{HCl}$ & Quercetin & 1.06 & 1.37 & 0.98 & 1.04 & 1.63 & 0.98 \\
\hline $0.5 \mathrm{M} \mathrm{H}_{2} \mathrm{SO}_{4}$ & Quercetin & 1.28 & 1.06 & 0.98 & 1.08 & 1.02 & 0.97 \\
\hline
\end{tabular}

The adsorption parameters for the kinetic-thermodynamics models showed that the values of the number of active sites resided by a single molecule $1 / \mathrm{y}$ are bigger than unity, for both $\mathrm{RC}$ leaf extract and Quercetin, in $0.5 \mathrm{M} \mathrm{HCl}$ and $0.5 \mathrm{M} \mathrm{H}_{2} \mathrm{SO}_{4}$, at $30{ }^{\circ} \mathrm{C}$. This indicates that the molecules of the RC leaf extract and of Quercetin fill more than one active site. However, only $1 / y$ for $\mathrm{RC}$ in $0.5 \mathrm{M} \mathrm{H}_{2} \mathrm{SO}_{4}$ indicates that it occupies less than one active site. This gives a key clue to the fact that the acidic anion is playing an important role in the inhibitor adsorption mechanism 
onto the metal surface, since values for Quercetin are the same in both acidic media, while for the plant extract (RC) they differ between $\mathrm{HCl}$ and $\mathrm{H}_{2} \mathrm{SO}_{4}$, which suggests the possible interaction of another chemical ingredient [25]. In addition to that, the values of the binding constant, $K$, which show how stronger or weak an interaction between the inhibitor molecule and the metal is, are the same for Quercetin, in both acidic media, indicating that there is no effect of the acidic anion on this interaction [26]. However, when using the plant extract, $\mathrm{K}$ is greater in $\mathrm{HCl}$ than in $\mathrm{H}_{2} \mathrm{SO}_{4}$, indicating the effect of the acidic anion on another chemical ingredient, which could be highly adsorbed and cause this strong interaction. More information was obtained from Flory-Huggins isotherm, and the value of the size parameter, $\mathrm{x}$, which is a measure of the number of adsorbed water molecules substituted by inhibitor molecules, is very close to that obtained from the kinetic model. Therefore, the results obtained for $1 / y$ and $x$ together cause one to think that the inhibitor molecule is so bulky that can occupy more than one active site, when adsorbed onto the metal surface [27].

\section{Effect of temperature}

Another valuable factor that could influence the metal corrosion rate, and change the inhibitor adsorption onto the electrode surface, is temperature.

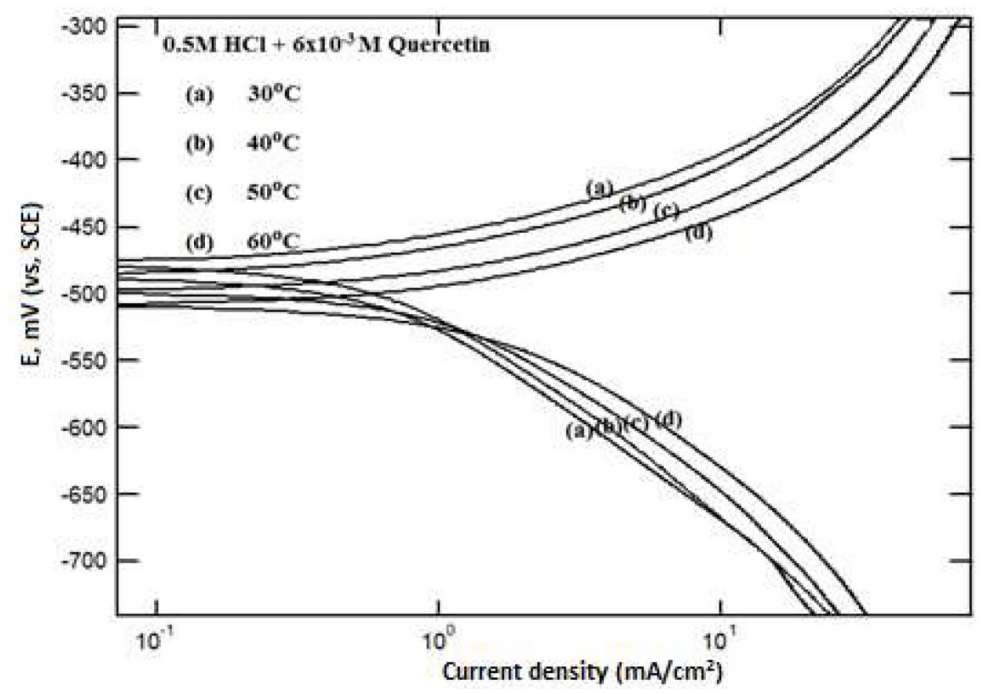

Figure 7. Potentiodynamic polarization curves for mild steel, in $0.5 \mathrm{M} \mathrm{HCl}$, in the presence of 0.75 g.L $\mathrm{L}^{-1}$ of Quercetin, at different temperatures.

The curves in Fig. 7 for Quercetin, with mild steel, in the absence and presence of $0.5 \mathrm{M} \mathrm{HCl}$, at different temperatures, correspond to the potentiodynamic polarization curves. Similar curves were observed for RC leaf extract and for Quercetin, in $0.5 \mathrm{M} \mathrm{H}_{2} \mathrm{SO}_{4}$, respectively.

The inhibition efficiency decreases with increasing temperature, as it is seen in Fig. 7. This is due to the increased rate of mild steel dissolution process, with the contribution of the partial inhibitor desorption from the metal surface, with the increase in temperature [28, 29]. Thus, the corrosion rate increases as the desorption of the adsorbed film onto the mild steel surface increases. 
Similar observations were obtained for RC leaf extract and for Quercetin, in $0.5 \mathrm{M} \mathrm{H}_{2} \mathrm{SO}_{4}$ (Fig. 7 and Fig. 8). The values of the apparent activation energy ( $\left.\mathrm{E}_{\mathrm{a}}\right)$, obtained in the inhibitor presence and absence, could give some information about the mechanism of inhibition that took place.

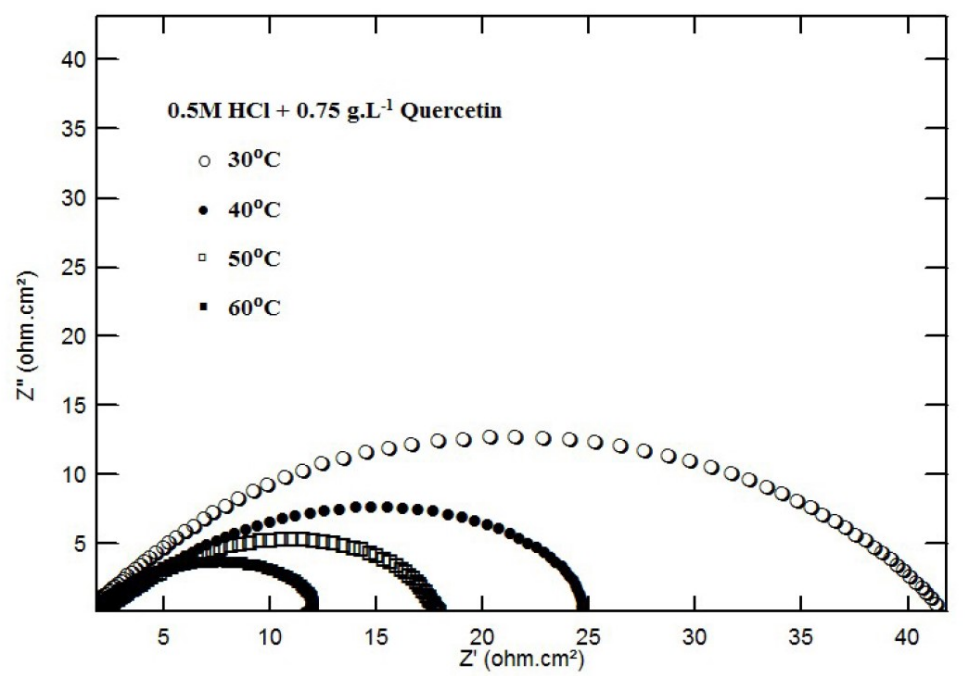

Figure 8. Nyquist impedance plots for mild steel, in $0.5 \mathrm{M} \mathrm{HCl}$, in the presence of 0.75 g.L ${ }^{-1}$ of Quercetin, at different temperatures.

The thermodynamic parameters, including activation energy, $E_{a}$, activation enthalpy, $\Delta \mathrm{H}^{*}$ a, and the apparent entropy of activation, $\Delta \mathrm{S}^{*}$, were computed from Arrhenius equation and from the transition state equation mentioned in [12].

The binding constant, K, was determined from the equation below [30].

$$
\mathrm{K}_{\mathrm{ads}}=\frac{1}{55.5} e^{\frac{-\Delta \mathrm{Gads}}{\mathrm{RT}}}
$$

where $\Delta \mathrm{G}_{\mathrm{ads}}$ is the standard free energy of adsorption, $\mathrm{T}$ is the absolute temperature in Kelvin, $\mathrm{R}$ is the molar gas constant and 55.5 represent the concentration of water in the solution, expressed in molar.

The calculated values for the activation parameters, together with $\Delta \mathrm{G}_{\mathrm{ads}}$, are given in Table 4. The obtained data show that $E_{a}$ values increased in the presence of RC extract and of Quercetin, compared to the blank, which indicates physical adsorption, where the chemical species of the extract caused geometric blocking of the metal surface [31]. Also, the average value calculated for the difference of $E_{a}$ $\Delta \mathrm{H}^{*}$, for $\mathrm{RC}$ and Quercetin. is $2.64 \mathrm{~kJ} / \mathrm{mol}$, in $0.5 \mathrm{M} \mathrm{HCl}$ and $0.5 \mathrm{M} \mathrm{H}_{2} \mathrm{SO}_{4}$, which is very similar to the average value of RT, that is $2.63 \mathrm{~kJ} / \mathrm{mol}$, at $30{ }^{\circ} \mathrm{C}$. This gives the idea that the corrosion process was taking place through a unimolecular reaction, as it is given by the following equation [32]:

$$
\mathrm{Ea}-\Delta \mathrm{H}^{*}=\mathrm{RT}
$$

From Table 4 , it is clear that all $\Delta \mathrm{H}^{*}$ values are positive, which reveals that the formation process of the activated complex is endothermic. Also, the magnitude of the enthalpy is lower than $80 \mathrm{~kJ} / \mathrm{mol}$, indicating a physical adsorption process, since the enthalpy of chemisorption process approaches $100 \mathrm{~kJ} / \mathrm{mol}$. The negative 
$\Delta \mathrm{S}^{*}$ values $\left(\mathrm{A}=\pi \mathrm{r}^{2}\right.$ complex $)$ in the rate determining step represent an association step rather than a dissociation step. This gives rise to the fact that more orderings taking place on going from reactants to the activated complex [33-35].

Table 4. The activation parameters of mild steel in $0.5 \mathrm{M} \mathrm{HCl}$, in the absence and presence of 0.75 g. $\mathrm{L}^{-1}$ of RC leaf extracts and of Quercetin, respectively.

\begin{tabular}{|c|c|c|c|c|c|}
\hline \multirow{2}{*}{ Acid solution } & Inhibitor & $\begin{array}{c}\mathbf{E} \mathbf{a} \\
\mathbf{k J . m o l}\end{array}$ & $\begin{array}{c}\mathbf{\Delta} \mathbf{H}^{*} \\
\mathbf{k J . m o l}\end{array}$ & $\begin{array}{c}\Delta \mathbf{S}^{*} \\
\mathbf{J . m o l}^{-\mathbf{1}} \cdot \mathbf{K}^{-\mathbf{1}}\end{array}$ & $\begin{array}{c}\Delta \mathbf{G}_{\mathbf{a d s}} \\
\mathbf{k J . m o l}\end{array}$ \\
\hline \multirow{3}{*}{$0.5 \mathrm{M} \mathrm{HCl}$} & - & 31.79 & 29.16 & -172.59 & - \\
\cline { 2 - 6 } & RC & 46.11 & 43.47 & -135.27 & -13.58 \\
\cline { 2 - 6 } & Quercetin & 40.41 & 37.77 & -148.63 & -10.26 \\
\hline \multirow{2}{*}{$0.5 \mathrm{M} \mathrm{H}_{2} \mathrm{SO}_{4}$} & - & 13.86 & 11.23 & -166.63 & -11.59 \\
\cline { 2 - 6 } & RC & 49.81 & 47.17 & -120.45 & -10.74 \\
\hline
\end{tabular}

The process of adsorption of RC leaf extract and of Quercetin was spontaneous, as shown by $\Delta \mathrm{G}_{\mathrm{ads}}$ negative values. Also, these values indicate the stability of the adsorbed layers onto the mild steel surface, in the $0.5 \mathrm{M} \mathrm{HCl}$ and $0.5 \mathrm{M} \mathrm{H}_{2} \mathrm{SO}_{4}$ solutions. Generally, the physisorption mechanism, which is an electrostatic interaction between the charged molecules and the metal surface, corresponds to $\Delta \mathrm{G}_{\text {ads }}$ values up to $-20 \mathrm{~kJ} . \mathrm{mol}^{-1}$. However, chemisorption mechanism, which could be the sharing or transfer of an electron pair or $\pi$ electrons, from the inhibitor molecule to the metal surface, to form a coordinate bond, represents values around $-40 \mathrm{~kJ} \mathrm{moL}^{-1}$ or more negative $[31,36]$. The obtained results suggest that the adsorption of RC leaf extract and of Quercetin onto the metal surface is physisorption rather than chemisorption

\section{Conclusions}

The results presented in this paper show that Rhus Coriaria $(R C)$ leaf extracts inhibit mild steel corrosion in a $\mathrm{HCl}$ solution, more than in $\mathrm{H}_{2} \mathrm{SO}_{4}$ solution, and leaf extracts were more promising than active chemical components in both acidic media.

Also, the inhibition efficiencies of the RC leaf extract and of one of its chemical components, Quercetin, increase with higher concentrations and decrease with increasing temperature, suggesting an inhibition mechanism through the formation of a protective film that blocks active corrosive sites on the metal surface, via physical adsorption.

However, the results of AFM surface morphology confirm the formation of a film on the mild steel surface, which is responsible for the decrease in the surface roughness and, in its turn, effectively retards steel corrosion.

Moreover, Flory-Huggins isotherm and kinetic - thermodynamic model indicate that the corrosion process is a unimolecular reaction, and that the acidic anion is playing an important role in the inhibitor adsorption onto the metal surface. 
Finally, results from all the employed techniques are in reasonably good agreement, and point to the fact that $\mathrm{RC}$ leaf extract is a better inhibitor than Quercetin, within the range of investigated concentrations.

Therefore, the plant extract can be considered as a good source of corrosion inhibitors which are relatively cheap, non-toxic, biodegradable and effective in an acidic medium.

\section{Acknowledgement}

This work was supported by National Council for Scientific Research (CNRS), reference number 05-13-12.

\section{References}

1. Mourya P, Banerjee S, Rastogi RB, et al. Inhibition of Mild Steel corrosion in Hydrochloric and Sulfuric Acid media using a Thiosemicarbazone Derivative. Ind Eng Chem. 2013;52:12733-12747. https://doi.org/10.1021/ie4012497.

2. Issaadi S, Douadi T, Zouaoui A, et al. Novel thiophene symmetrical Schiff base compounds as corrosion inhibitor for mild steel in acidic media. Corros Sci. 2011;53:1484-1488. https://doi.org/10.1016/j.corsci.2011.01.022.

3. El Bribri A, Tabyaoui M, Tabyaoui B, et al. The use of Euphorbia falcata extract as eco-friendly corrosion inhibitor of carbon steel in hydrochloric acid solution. Mater Chem Phys. 2013;141:240-247. https://doi.org/10.1016/j.matchemphys.2013.05.006.

4. Ajmal M, Mideen AS, Quraishi MA. 2-hydrazino-6-methyl-benzothiazole as an effective inhibitor for the corrosion of mild steel in acidic solutions. Corros Sci. 199436:79-84. https://doi.org/10.1016/0010-938X(94)90110-4.

5. Al-Otaibi MS, Al-Mayouf AM, Khan M, et al. Corrosion inhibitory action of some plant extracts on the corrosion of mild steel in acidic media. Arab J Chem. 2012;7:17. https://doi.org/10.1016/j.arabjc.2012.01.015.

6. Srivastava M, Tiwari P, Srivastava SK, et al. Low cost aqueous extract of Pisumsativum peels for inhibition of mild steel corrosion. J Mol Liq. 2018;253:357-368. https://doi.org/10.1016/j.molliq.2018.01.137.

7. Deng SD, Li XH. Inhibition by Ginkgo leaves extract of the corrosion of steel in $\mathrm{HCl}$ and H2SO4 solution. Corros Sci. 2012;55:407-415. https://doi.org/10.1016/j.corsci.2011.11.005.

8. Pereira SSAA, Pegas MM, Fernandez TL, et al. Inhibitory action of aqueous garlic peel extract on the corrosion of carbon steel in $\mathrm{HCl}$ solution. Corros Sci. 2012;65:360-366. https://doi.org/10.1016/j.corsci.2012.08.038.

9. Raja PB, Qureshi AK, Rahim AA, et al. Neolamarckiacadamba alkaloids as eco-friendly corrosion inhibitors for mild steel in $1 \mathrm{M} \mathrm{HCl}$ media. Corros Sci. 2013;69:292-301. http://dx.doi.org/10.1016/j.corsci.2012.11.042.

10. Soltani N, Tavakkoli N, Khayatkashani M, et al. Green approach to corrosion inhibition of 304 stainless steel in hydrochloric acid solution by the extract of 
Salvia officinalis leaves. Corros Sci. 2012;62:122-135. https://doi.org/10.1016/j.corsci.2012.05.003.

11. Li LG, Zhang XP, Lei JL, et al. Adsorption and corrosion inhibition of Osmanthusfragran leaves extract on carbon steel. Corros Sci. 2012;63:82-90. https://doi.org/10.1016/j.corsci.2012.05.026.

12. Rahal HT, Abdel-Gaber AM, Younes GO. Inhibition of Steel Corrosion in Nitric Acid by Sulfur Containing Compounds. Chem Eng Commun. 2016;203:435-445. https://doi.org/10.1080/00986445.2015.1017636.

13. Shabbir A. Linn Rhus Coriaria Linn, a Plant of Medicinal, Nutritional and Industrial Importance: A review. J Anim Plant Sci. 2012;22:505-512.

14. Amin MA, Abd El Rehim SS, Abdel-Fatah HT. Electrochemical frequency modulation and inductively coupled plasma atomic emission spectroscopy methods for monitoring corrosion rates and inhibition of low alloy steel corrosion in $\mathrm{HCl}$ solutions and a test for validity of the Tafel extrapolation method. Corros Sci. 2009;51: 882-894. https://doi.org/10.1016/j.corsci.2009.01.006.

15. Abdel-Gaber AM, Abd-El-Nabey BA, Sidahmed IM, et al. Inhibitive Action of Some Plant Extracts on the Corrosion of Steel in Acidic Media. Corros Sci. 2006;48:2765. https://doi.org/10.1016/j.corsci.2005.09.017.

16. Ostovari A, Hoseinieh SM, Peikari M, et al. Corrosion inhibition of mild steel in $1 \mathrm{M} \mathrm{HCl}$ solution by henna extract: a comparative study of the inhibition by henna and its constituents (Lawsone, Gallic acid, a-D-Glucose and Tannic acid). Corros Sci. 2009;51:1935-1949. https://doi.org/10.1016/j.corsci.2009.05.024.

17. Reis FM, Melo HG, Costa I. EIS investigation on Al 5052 alloy surface preparation for self-assembling monolayer. Electrochim Acta. 2006;51:1780-1788. https://doi.org/10.1016/j.electacta.2005.02.118.

18. Sathiya Priya AR, Muralidharam VS, Subramania A. Development of novel acidizing inhibitors for carbon steel corrosion in $15 \%$ boiling hydrochloric acid. Corrosion. 2008;64:541-552. https://doi.org/10.5006/1.3278490.

19. Hsu CS, Mansfeld F. Concerning the conversion of the constant phase element parameter Yo into a capacitance. Corrosion. 2001;57:747-748. https://doi.org/10.5006/1.3280607.

20. Bentiss F, Lagrenee M, Traisnel M, et al. The corrosion inhibition of mild steel in acidic media by a new triazolederivative. Corros Sci. 1999; 789-803. https://doi.org/10.1016/S0010-938X(98)00153-X.

21. Popova A, Sokolova E, Raicheva S, et al. AC and DC study of the temperature effect on mild steel corrosion in acid media in the presence of benzimidazole derivatives. Corros Sci. 2003;45:33-58. https://doi.org/10.1016/S0010-938X (02)00072-0.

22. Seo Y, Jhe W, Hwang CS. Atomic force microscopy and spectroscopy. Rep. Prog Phys. 2008;71:151. https://doi.org/stacks.iop.org/RoPP/71/016101.

23. Nasibi M , Mohammady M , Ghasemi E, et al. J Adhes Sci Tech. 2013;27:56-68. 
24. Satapathy AK, Gunasekaran G, Sahoo SC, et al. Corrosion inhibition by Justiciagendarussa plant extract in hydrochloric acid solution. Corros Sci. 2009;51:2848-2856. https://doi.org/10.1016/j.corsci.2009.08.016.

25. Abdel-Gaber AM, Abd-El-Nabey BA, Saadawy M. The role of acid anion on the inhibition of the acidic corrosion of steel by lupine extract. Corros Sci. 2009;51:1038-104. https://doi.org/10.1016/j.corsci.2009.03.003

26. Abd-El-Nabey BA, Abdel-Gaber AM, Elawady GY, et al. Inhibitive Action of Some Plant Extracts on the Alkaline Corrosion of Aluminum. Int $\mathrm{J}$ Electrochem Sci. 2012;7:7823 - 7839.

27. Abdel-Gaber AM, Masoud MS, Khalil EA, et al. Electrochemical study on the effect of Schiff base and its cobalt complex on the acid corrosion of steel. Corros Sci. 2009;51:3021-3024. https://doi.org/10.1016/j.corsci.2009.08.025.

28. Yameng Q, Hongyun L, Shuqi Z, et al. Effect of temperature on the corrosion behavior of Carbon Steel in Hydrogen Sulphide environments. Int J Electrochem Sci. 2014;9:2101-2112.

29. Dehri I, Özcan M. The effect of temperature on the corrosion of mild steel in acidic media in the presence of some sulphur-containing organic compounds. Mater Chem Phys. 2006;98:316-323. https://doi.org/10.1016/j.matchemphys.2005.09.020.

30. Ashassi-Sorkhabi H, Shaabani B, Aligholipour B, et al. The effect of some Schiff Bases on the corrosion of Aluminium in HCl Solution. Appl Surf Sci. 2006;252:4039-4047. https://doi.org/10.1016/j.apsusc.2005.02.148.

31. Tebbji K, Faska N, Tounsi A, et al. The effect of some lactones as inhibitors forthe corrosion of mild steel in $1 \mathrm{M}$ hydrochloric acid. Mater Chem Phys. 2007;106:260-267. https://doi.org/10.1016/j.matchemphys.2007.05.046.

32. Awe IC, Abdulrahaman AS, Ibrahim HK, et al. Inhibitive performance of Bitter Leaf root extract on Mild Steel corrosion in sulphuric acid solution. Am J Mat Eng Tech. 2015;3:35-45.

33. Khalifa OR, Abdallah SM. Corrosion Inhibition of Some Organic Compounds on Low Carbon Steel in Hydrochloric Acid Solution. Port Electrochim Acta. 2011;29:47-56. https://doi.org/10.4152/pea.201101047.

34. Saqalli L, Galai M, Gharda N, et al. Corrosion Inhibition of Carbon Steel by Anthraquinones Derivatives in $1.0 \mathrm{M} \mathrm{HCl}$ : Electrochemical and Quantum Calculations. Int J Electrochem Sci. 2018;13:5096-5119. https://doi.org/10.20964/2018.05.40.

35. El Ouali I, Hammouti B, Aouniti A, et al. Thermodynamic characterisation of steel corrosion in $\mathrm{HCl}$ in the presence of 2- phenylthieno $(3,2-\mathrm{b})$ quinoxaline. J Mater Envir Sci. 2010;1:1-8.

36. Noor E A. Evaluation of inhibitive action of some quaternary N-heterocyclic compounds on the corrosion of $\mathrm{Al}-\mathrm{Cu}$ alloy in hydrochloric acid. Mater Chem Phys. 2009;114:533-541. https://doi.org/10.1016/j.matchemphys.2008.09.065. 